$\S=$

\title{
Anatomical variations of the hepatobiliary system in Sudanese patients undergoing endoscopic retrograde cholangiopancreatography (ERCP)
}

\author{
Wael Mohialddin Ahmed Doush ${ }^{1 *}$, Mohammed Ahmed Hassan A/Galil ${ }^{1}$, Shakir Z. Ibrahim ${ }^{2}$ \\ ${ }^{1}$ Department of Anatomy, Faculty of Medicine, University of Khartoum, Khartoum, Sudan \\ ${ }^{2}$ Department of Surgery, Faculty of medicine, University of Khartoum, Khartoum, Sudan \\ *Corresponding author: Dr.Wael Mohialddin Ahmed Doush, Assistant Professor of General Surgery, \\ MD; MRCSEd., E-mail: dr.waelmohialddin11@hotmail.com
}

\begin{abstract}
Background: The meticulous identification of the hepatobiliary tree system normal anatomy during surgical operations is crucial in iatrogenic injury prevention. Equally important, an understanding of the congenital variations of biliary and vascular anatomy, as the literature abounds with reports of specific anatomical variations, and their surgical implications.

Aim: This study aimed to study the presence of anatomical variations within the hepatobiliary system in Sudanese population undergoing endoscopic retrograde cholangiopancreatography (ERCP).

Patients and methods: The records of patients undergoing ERCP in Soba University Hospital during 2004 to 2008 were analyzed. There were 277 Sudanese patients who had complained of right hypochondrial abdominal pain \& history of jaundice (obstructive jaundice) that underwent ERCP were included within this study. The exclusion criteria included the following: Sudanese patients in whom ERCP failed or patients who had advanced hepatobiliary disease like cancers, strictures either cancerous or iatrogenic, fistula and iatrogenic biliary leak.

Results: The analysis of 277 Sudanese patients undergoing ERCP of the hepatobiliary system showed the following results regarding the variations: The choledochal cyst type one (fusiform type) was present in $3(1.08 \%)$ patients; very low cystic duct insertion (parallel) was present in $1(0.36 \%)$ patient and long cystic duct was present in $3(1.08 \%)$ patients. The ampulla of Vater size variations occurred as A) Normal in 158 (57\%) patient, B) Small in 56 (20.2\%) patients, C) Large in 29 (10.5\%) patients, D) Periampullary diverticula in 4 (1.4\%) patients and E) unclassified in $30(10.8 \%)$ patients. Other forms of congenital anomalies were not found.

Conclusion: The using of endoscopic retrograde cholangiopancreatography (ERCP) is a reliable radiological method for depicting congenital anomalies of the hepatobiliary system, but it is an invasive procedure.
\end{abstract}

Keywords: Ampulla of Vater; Anatomy; Congenital Variations; Choledochal Cyst; Cystic Duct; Endoscopic Retrograde Cholangiopancreatography; Sudan..

\section{Introduction}

The meticulous identification of the hepatobiliary tree system normal anatomy during surgical operations is crucial in iatrogenic injury prevention. Equally important, an understanding of the congenital variations of biliary and vascular anatomy, as the literature abounds with reports of specific anatomical variations, and their surgical implications (Williams 1980). In recent years the technology had developed and the using of imaging modalities gave the possibility to study the hepatopancreatico-biliary system includes computed tomography (CT) scans, magnetic resonance cholangiopancreatography (MRCP), percutaneous transhepatic cholangiography (PTC), contrast-enhanced (MRCP) and intraoperative cholangiography (Nayman and Özbek 2016). Endoscopic cannulation of the ampulla of Vater was first reported in 1968. Since that time, the endoscopic retrograde cholangiopancreatography (ERCP) was established worldwide rapidly and became a very useful tool for diagnosis and therapy in biliary and pancreatic diseases. In clinical practice, sphincterotomy was beginning to use in the mid-1970s and biliary stenting five years after that (Leung 2005).
This study reviews the congenital variations of extrahepatic biliary anatomy in Sudanese patients undergoing endoscopic retrograde cholangiopancreatography (ERCP). Further studies on image techniques and hepatobiliary scintigraphy for diagnosis of biliary diseases may details of the whole biliary ductal system and show some kinds of biliary malformation, which are clinically important such as an anomalous arrangement of the pancreatico-biliary ductal system, congenital biliary strictures and congenital dilatation of the intrahepatic bile duct associated with choledochal cyst.

\section{Patients and methods}

This is a descriptive - retrospective hospital-based study carried at the Soba University Hospital; Sudan for four years. The author collected data from records of patients undergoing (ERCP) at Soba University Hospital during 2004 to 2008. There were 277 Sudanese patients who had complained of right hypochondrial abdominal pain \& history of jaundice (obstructive jaundice) that underwent ERCP were included within this study. The exclusion criteria included the following: Sudanese patients in whom ERCP failed or patients who had advanced 
hepatobiliary disease like cancers, strictures either cancerous or iatrogenic, fistula and iatrogenic biliary leak.

Patients were referred by consultants got an appointment, and the procedure was explained and consent was taken for the hospital administration to collect data from these patients and given an explanation for preparation include fasting 6 hours at least. Investigations are ready, which are bleeding time, hemoglobin $(\mathrm{Hb} \%)$, blood grouping, platelets count and ultrasound images. Then patients go to the comfortable X-ray room containing side view duodenoscope Olympus CLV -U 40 and appropriate ERCP accessories as catheters, contrast and emergency drugs.

Before the procedure, the patients were asked to remove dentures, eye glasses and contact lenses. Then they were asked about the history of any allergic reactions to any medications or contrast dye. Diathermy cuff was put under the upper-right leg. After wearing a hospital gown, the patient was asked to lie on $\mathrm{x}$-ray table, the left arm behind his back to facilitate rotating into the prone position (Oblique prone position). Endoscopist \& their assistants wear a protective lead apron, and then started the procedure after sedating patient intravenously with pethedin $25 \mathrm{mg}$ and diazepam 5mg. Endoscopic tube was introduced through mouth/esophagus/stomach until it reaches second part of duodenum, then the ampulla was identified. Cholangiographic catheter was introduced \& radiocontrast dye injected to common bile duct $\&$ extrahepatic ducts until reach intrahepatic ducts. Selected still images obtained on X-ray film and the film preparation was done by radiology technicians using X-ray machine KXO - ISE model and X-Omat film processor. The interpretation of radiological film was carried out by senior endocopist.

Then the data were arranged on a master sheet. The author analyzed data using the computer program (SPSS) version 15.1 for evaluation of the results.

\section{Results}

In this study of 277 cases, $156(56.3 \%)$ were females and the remaining $121(43.7 \%)$ were males, and the majority of anatomical variations present in our study seen in females, (Table 1). The peak incidence of patient's age for the hepatobiliary system variations discovery was ranged between 46 - 60yrs (middle age), which represent $30.68 \%$, (Figure 2).

The analysis of 277 Sudanese patients undergoing ERCP of the hepatobiliary system showed the following results regarding the variations: The choledocal cyst type 1 (fusiform type) was present in $3(1.08 \%)$ patients; very low cystic duct insertion (parallel) was present in 1 $(0.36 \%)$ patient and the long cystic duct was present in $3(1.08 \%)$ patients, (Table 2).

The ampulla of Vater size variations occurred as A) Normal in $158(57 \%)$ patient, B) Small in 56 (20.2\%) patients, C) Large in 29 (10.5\%) patients, D) Periampullary diverticula in $4(1.4 \%)$ patients and E) unclassified in 30 (10.8\%) patients, (Table 3 ).

Other forms of congenital anomalies were not found in this study.

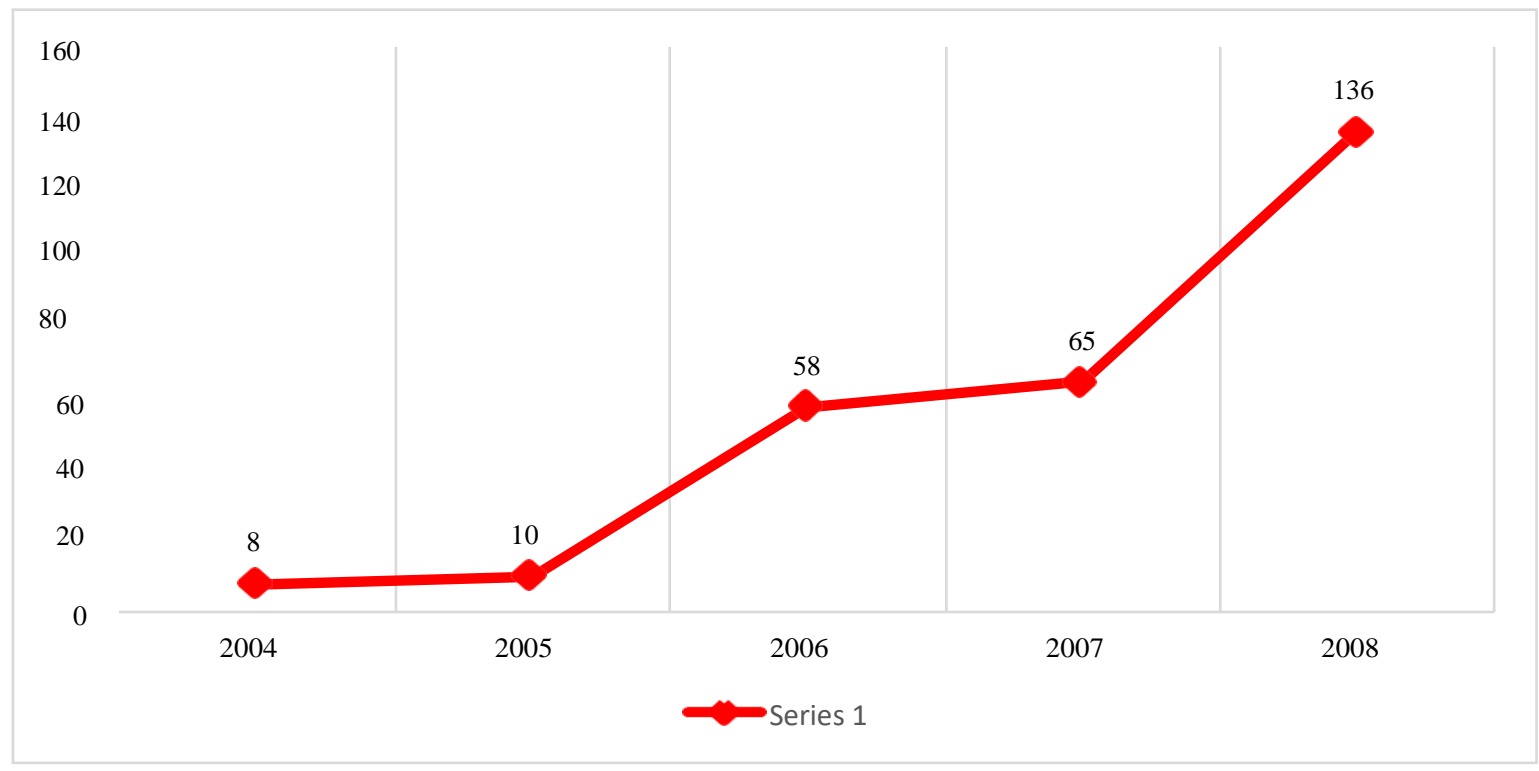

Fig. 1: The Total Number of Cases per Year

Table 1: The Gender Distribution

\begin{tabular}{lll}
\hline Gender & Frequency & Percent \\
\hline Male & 121 & $43.7 \%$ \\
Female & 156 & $56.3 \%$ \\
Total & 277 & $100 \%$ \\
\hline
\end{tabular}




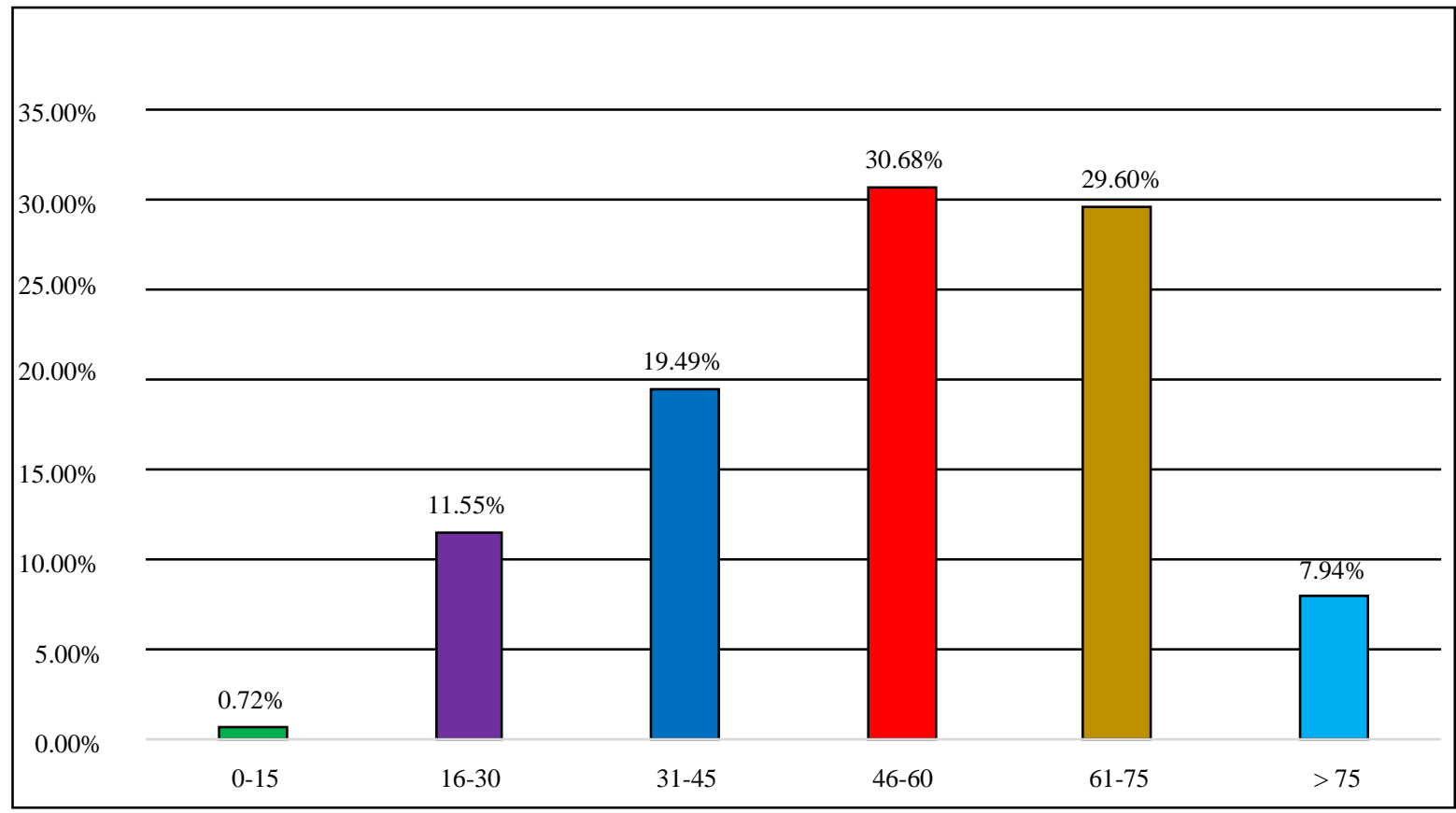

Fig. 2: Age Distribution.

Table 2: Congenital Anomalies and Variation of Hepatobiliary System

\begin{tabular}{lll}
\hline Variation & Frequency & Percent \\
\hline Choledocal cyst (Type 1 - Fusiform shape) & 3 & $1.08 \%$ \\
Very low cystic duct insertion (Pararell Type) & 1 & $0.36 \%$ \\
Long cystic Duct & 3 & $1.08 \%$ \\
Normal cases & 270 & $97.5 \%$ \\
Total Number & 277 & $100 \%$ \\
\hline
\end{tabular}

Table 3: Anatomical Variations in the Size of the Ampulla of Vater

\begin{tabular}{lll}
\hline Ampulla of Vater size & Frequency & Percent \\
\hline Normal & 158 & $57 \%$ \\
Small & 56 & $20.2 \%$ \\
Large & 29 & $10.5 \%$ \\
Periampullary diverticula & 4 & $1.4 \%$ \\
Unclassified & 30 & $10.8 \%$ \\
Total & 277 & $100 \%$ \\
\hline
\end{tabular}

\section{Discussion}

When performing any hepatobiliary procedure, the frequent congenital variations full knowledge is required for iatrogenic injury prevention. In Sudan, no postmortem study, the high cost of magnetic resonance image (MRI) and intraoperative cholangiography not done as routine investigation just in a few centers. The endoscopic retrograde cholangiopancreatography (ERCP) is a direct contrast study of the pancreatic and hepatobiliary tree system. It is beneficial in the diagnosis and treatment of diseases such as developmental anomalies, strictures, and stones. Accordingly, the present study focuses on the presence of anatomical variations of the hepatobiliary system by analyzing ERCP cases from (2004-2008). The total cases are 277 presented as 2004 (8 cases), 2005 (10 cases), 2006 (58 cases), 2007 (65 cases) and 2008 (136 cases), (Figure 1). Out of the 277cases, 121(43.7\%) were males and $156(56.3 \%)$ were females, (Table 1).The majority of variations present in our study seen in females, and this result goes with the literature. Furthermore, another study revealed cystic duct variations appeared higher with female gender $66.67 \%$ than the males 33.34\% (Ahmad et al. 2016). Also, the choledochal cyst is more prevalent in females than males by a ratio over the range of 3:1 to $4: 1$ (Sarin et al. 1994).

The peak incidence of patient's age for the hepatobiliary system variations discovery was ranged between 46 - 60yrs (middle age), which represent $30.68 \%$. Previous studies reviewed did not mention the age, (Figure 2 ). The anatomical variations of the cystic duct are usually of no clinical significance. We found one case $(0.36 \%)$ had a very low cystic duct insertion in common hepatic duct, (Table 2). This less than figures found in international data. This variation incidence varied from
$8.3 \%$ to $14 \%$ in an autopsy series (Lamah 2001). In Korea, 10,243 ERCP cases were studied in a prospective way showed the cystic duct variations in $16.9 \%$ of the patients. Low union with the common hepatic duct (CHD) found in $9 \%$ of cases and a spiral passing to the common hepatic duct either anteriorly or posteriorly in $7.9 \%$ of patients (Kim et al. 2002). Also, we found long cystic duct in $3(1.08 \%)$ of cases, (Table 2).The cystic duct length measured from common bile duct up to gallbladder was $13.4-39 \mathrm{~mm}$ (27.4 mm on the average) (Myles 1937).

We reported in this study, gross dilatation (fusiform shape) in the middle of the common bile duct (CBD) in $3(1.08 \%)$ of cases diagnosed as choledochal cyst type one, (Table 2). The majority of cases were diagnosed in adult females complaining of right hypochondrial pain and jaundice. This result is very low when compared to the literature and the Todani classification, in which $80-90 \%$ of cases represent this type (Lipsett et al. 1997). In fact, $60-80 \%$ of adults with choledochal cysts had complications like stone formation and cystic wall carcinoma, especially type one choledochal cyst showed a higher cancer incidence (Ishibashi et al. 1997). In the clinical practice, wide (ERCP) utilization recognized increasingly the anatomic abnormalities of biliary system entry into the upper gastrointestinal tract. Our study revealed that common bile duct distal end terminated in the descending duodenum in all Sudanese patients included in this study. The anomalous opening of the common bile duct termination into the second part of the duodenal bulb was defined as the failure to demonstrate a papilla on its original site. Keddie et al. Investigated 120 patients and reported that common bile duct termination anomalies in $23 \%$ of cases. Another intraoperative cholangiograms study of biliary tract surgery for 1000 unselected patients showed that the common bile duct entered the descending duodenum in $86.9 \%$ of patients. It entered the junction between the descending and transverse duodenum, 
and the transverse duodenum in $13.1 \%$ of cases (Keddie et al. 1974) There were studies of 100 dissections found no termination distal to the junction of the second and third parts of the duodenum. Furthermore, the termination of the common bile duct in the proximal portion of the third part of the duodenum in 16 of 196 cadavers represents about $8 \%$.Through a standard duodenotomy, the authors found the common bile duct terminations at the junction of the second and third part of duodenum $11 \%$ and terminations in the proximal $2 \mathrm{~cm}$ of the third part $11 \%$. Hence, these studies showed that the anomalous of common bile duct terminations distal to descending duodenum is not rare (Davenport et al. 1991).

The position of the ampulla of Vater located at mid-point of the second part of the duodenal concave surface. Its size and shape are variable, and in different subjects, it may be round or oval, and either sessile or pedunculated. This study investigated the ampulla of Vater size variables in 277 patients, and revealed normal size in $158(57 \%)$ patient, small size in $56(20.2 \%)$ patients, large size in $29(10.5 \%)$ patients, periampullary diverticula in $4(1.4 \%)$ patients and unclassified in $30(10.8 \%)$ patients, (Table 3). We reviewed the literature and there was no data found regarding the ampulla of Vater size variations. In 1930, there was autopsies study conducted at the Mayo clinic showed that $58 \%$ of duodenal diverticula found near the ampulla (Myles 1937).

The using of ERCP in a study of 694 cases revealed periampullary diverticula in $162(27.3 \%)$ of cases. Furthermore, $90.1 \%$ of cases increased seen after 50 years old and choledocholithiasis frequently saw in $58.5 \%$ (Chun 1997).

\section{Conclusions}

The using of endoscopic retrograde cholangiopancreatography (ERCP) is a reliable radiological method for depicting congenital anomalies of hepatobiliary system, but it is an invasive procedure.

\section{References}

[1] Williams, PL., 1980. Gray's Anatomy (36th ed). New York: Churchill Livingstone, pp. 1374- 1385

[2] Nayman, A., Özbek, O., Erol, S., Karakuș, H. and Kaya, H.E., 2016. Magnetic resonance cholangiopancreatography evaluation of intrahepatic bile duct variations with updated classification. Diagnostic and Interventional Radiology, 22(6), p.489. https://doi.org/10.5152/dir.2016.16051.

[3] Leung, J., 2005. Fundamentals of ERCP. Advanced Digestive Endoscopy: ERCP. Blackwell Science, p.1.

[4] Ahmad, M.A. Khan, N.M. and Asmatullah., 2016. Anatomical variations of hepatobiliary triangle in patients operated laparoscopically for gallbladder diseases from Lahore and Sahiwal. Punjab Univ. J.Zool., 31(1):pp.47-52. DOI:40-PUJZ-61023120/16/0047-0052

[5] Y. K., Sarin, C. S., Sharma, L.D., Agarwal, M. Zaffar and A.K. Sharma., 1994 Choledochal Cyst. Pediatric Surgery Giant, 31, pp. 215-217.

[6] Lamah, M., Karanjia, N.D. and Dickson, G.H., 2001. Anatomical variations of the extrahepatic biliary tree: review of the world literature. Clinical anatomy, 14(3), pp.167-172. https://doi.org/10.1002/ca.1028.

[7] Kim, H.J., Kim, M.H., Lee, S.K., Seo, D.W., Kim, Y.T., Lee, D.K., Song, S.Y., Roe, I.H., Kim, J.H., Chung, J.B. and Kim, C.D., 2002. Normal structure, variations, and anomalies of the pancreaticobiliary ducts of Koreans: a nationwide cooperative prospective study. Gastrointestinal endoscopy, 55(7), pp.889-896. https://doi.org/10.1067/mge.2002.124635.

[8] Myles, R.B., 1937. Anatomical Variations of the Stomach and Duodenum within the Abdominal Cavity. The British Journal of Radiology, 10(111), pp.237-260. https://doi.org/10.1259/0007-1285-10111-237.

[9] Lipsett, P.A., Segev, D.L. and Colombani, P.M., 1997. Biliary atresia and biliary cysts. Baillière's clinical gastroenterology, 11(4) pp.619-641. https://doi.org/10.1016/S0950-3528(97)90013-0.

[10] Ishibashi, T., Kasahara, K., Yasuda, Y., Nagai, H., Makino, S. and Kanazawa, K., 1997. Malignant change in the biliary tract after excision of choledochal cyst. British journal of Surgery, 84(12), pp.1687-1691. https://doi.org/10.1046/j.1365-2168.1997.02843.x.
[11] Keddie, N.C., Taylor, A.W. and Sykes, P.A., 1974. The termination of the common bile duct. British Journal of Surgery, 61(8), pp.623-625. https://doi.org/10.1002/bjs.1800610808.

[12] Davenport, M., Heaton, N.D. and Howard, E.R., 1991. Spontaneous perforation of the bile duct in infants. British journal of surgery, 78(9), pp.1068-1070. https://doi.org/10.1002/bjs.1800780912.

[13] Jong Ho Chun, 1997. A study of 162 cases of prei ampullary diverticulum. Korean J gastrointest endosc. 17, pp.778-788. 